\title{
Mobility and Binding Mechanisms of Glyphosate in Agricultural Soils
}

\author{
MiCHAEL GLASER $^{1}$, BRIAN K. RICHARDS ${ }^{2}$, TAMMO S. \\ STEENHUIS $^{2}$, LUDMILLA ARISTILDE ${ }^{2,3 *}$ \\ ${ }^{1}$ Civil and Environmental Engineering, Cornell University, \\ Ithaca, NY. ${ }^{2,3}$ Biological and Environmental Engineering, \\ Cornell University, Ithaca, NY. ${ }^{3}$ Civil and Environmental \\ Engineering, Northwestern University, Evanston, IL; \\ (*correspondence: ludmilla.aristilde@northwestern.edu)
}

Glyphosate is the most used herbicide in the world, offering broad-spectrum toxicity and the ability to suppress weeds at any stage of growth. Generally, the strong adsorption affinity between glyphosate and metal oxides in soil is thought to render glyphosate immobile [1]. However, glyphosate has become ubiquitous in surface waters, particularly downstream from agricultural lands, implying post-application mobility [2]. In fact, a recent study observed enhanced post-application glyphosate runoff following significant rain events [3]. Studies on glyphosate desorption and the responsible mechanics are lacking. Here adsorption and desorption experiments at various background salt conditions were conducted for glyphosate with agricultural soils representing two distinct hydrological regimes and with different iron content (Fig. 1). Liquid chromotography coupled with mass spectrometry was used to develop a non-derivatized method to quantify glyphosate. Molecular interactions in emerging glyphosate-soil complexes were monitored using Fourier-transform infrared spectroscopy and solid-state nuclear magnetic resonance. Our data imply that a considerable portion of adsorbed glyphosate is weakly bound and thus susceptible to mobility following rain events.

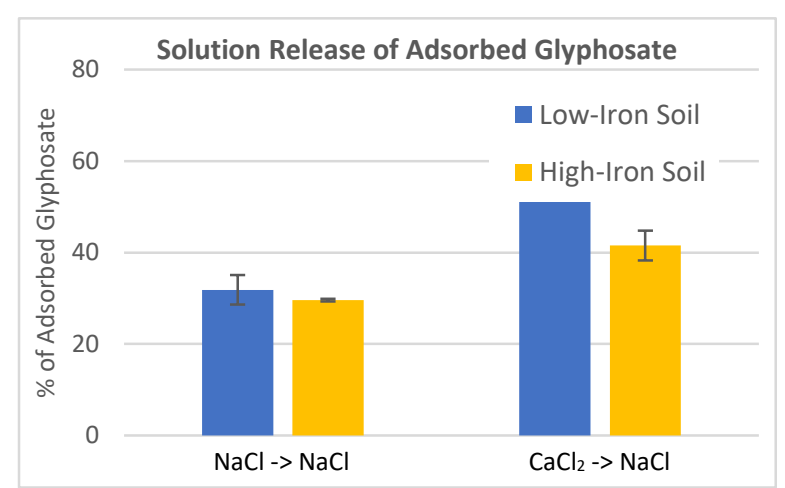

Figure 1. Release of glyphosate adsorbed on soil loaded at $\mathrm{I}=10 \mathrm{mM}$ $\mathrm{CaCl}_{2}$ or $\mathrm{NaCl}$ before exchange with desorption solution at $\mathrm{I}=1 \mathrm{mM}$ $\mathrm{NaCl}$.

[1] Kanissery, R., et al. Plants 8, 499 (2019). [2] Battaglin, W., et al. JAWRA 50, 275-290 (2014). [3] Richards, B. K. et al. Environ. Sci. \& Technol. 5, 249-254 (2018). 